\title{
Decarbonization of the steel industry. A techno-economic analysis
}

\author{
Amaia Sasiain Conde ${ }^{1, *}$, Katharina Rechberger ${ }^{1}$, Andreas Spanlang $^{1}$, Hermann Wolfmeir $^{2}$, and Christopher Harris ${ }^{2}$ \\ ${ }^{1}$ K1-MET GmbH, Low Carbon Energy Systems, Stahlstrasse 14, Linz 4020, Austria \\ ${ }^{2}$ Voestalpine Stahl GmbH, R\&D and Innovation, voestalpine-Strasse 3, Linz 4020, Austria
}

Received: 31 August 2021 / Accepted: 10 January 2022

\begin{abstract}
A substantial $\mathrm{CO}_{2}$-emmissions abatement from the steel sector seems to be a challenging task without support of so-called "breakthrough technologies", such as the hydrogen-based direct reduction process. The scope of this work is to evaluate both the potential for the implementation of green hydrogen, generated via electrolysis in the direct reduction process as well as the constraints. The results for this process route are compared with both the well-established blast furnace route as well as the natural gas-based direct reduction, which is considered as a bridge technology towards decarbonization, as it already operates with $\mathrm{H}_{2}$ and $\mathrm{CO}$ as main reducing agents. The outcomes obtained from the operation of a 6-MW PEM electrolysis system installed as part of the H2FUTURE project provide a basis for this analysis. The $\mathrm{CO}_{2}$ reduction potential for the various routes together with an economic study are the main results of this analysis. Additionally, the corresponding hydrogen- and electricity demands for large-scale adoption across Europe are presented in order to rate possible scenarios for the future of steelmaking towards a carbon-lean industry.
\end{abstract}

Keywords: direct reduction / $\mathrm{CO}_{2}$-emissions / production costs / break even ranges / energy demand / hydrogen demand

\section{Introduction}

This study encompasses a techno-economic analysis of the hydrogen-based crude steel production route, alongside the current production processes. Three different production routes were considered for the evaluation of the prospective development pathways of the steel industry towards a carbon free steel production: (1) the blast furnace route and the direct reduction with (2) natural gas and (3) hydrogen. The blast furnace route was considered as the reference technology for further calculations and the natural gasbased direct reduction as the bridge technology between the $\mathrm{BF} / \mathrm{BOF}$ and hydrogen-based route, which is operated almost without the utilization of carbonaceous fossil sources. Nevertheless, to obtain a $\mathrm{CO}_{2}$-lean steel production, the so-called "green hydrogen"; used as reducing gas for the production of crude steel must be generated from renewable energy, for example, through the electrolysis of water. An economic assessment of hydrogen-based production enables the evaluation of possible scenarios for the future of steelmaking and their corresponding impacts, analyzing the future demand of hydrogen and subsequently electricity for the conversion to carbon-lean processes. The

\footnotetext{
* e-mail: amaia.sasiain@k1-met.com
}

goal is to determine under which technical and economic conditions the production of steel through the hydrogen route becomes a feasible solution for the steel industry.

\section{State of the art}

Existing steel production in Europe is nearly entirely divided between: (1) the blast furnace in combination with the basic oxygen route; where steel is produced from virgin iron ore and (2) the electric arc furnace operated with scrap, where typically additional iron-bearing materials such as DRI may be added. Across the European Union, steel produced via the blast furnace route accounts for $58.5 \%$ of total production versus $41.5 \%$ of steel production, which is accomplished via the EAF route, as stated in the Steel Statistical Yearbook [1]. According to this report [1] and to comprehend the size of the iron and steel industry, 167.7 million tons of steel were produced in Europe at more than 500 production sites in 2018 (Fig. 1).

The two above-mentioned production routes, differ in both achievable steel product quality and $\mathrm{CO}_{2}$ emissions. In comparison with the scrap/EAF route, larger amounts of $\mathrm{CO}_{2}$ are emitted when producing steel from iron ores via the integrated blast furnace route, as showed by Dahlmann et al. [2], since carbon is required, both as reducing agent and as energy source. Nevertheless, steel that is produced 


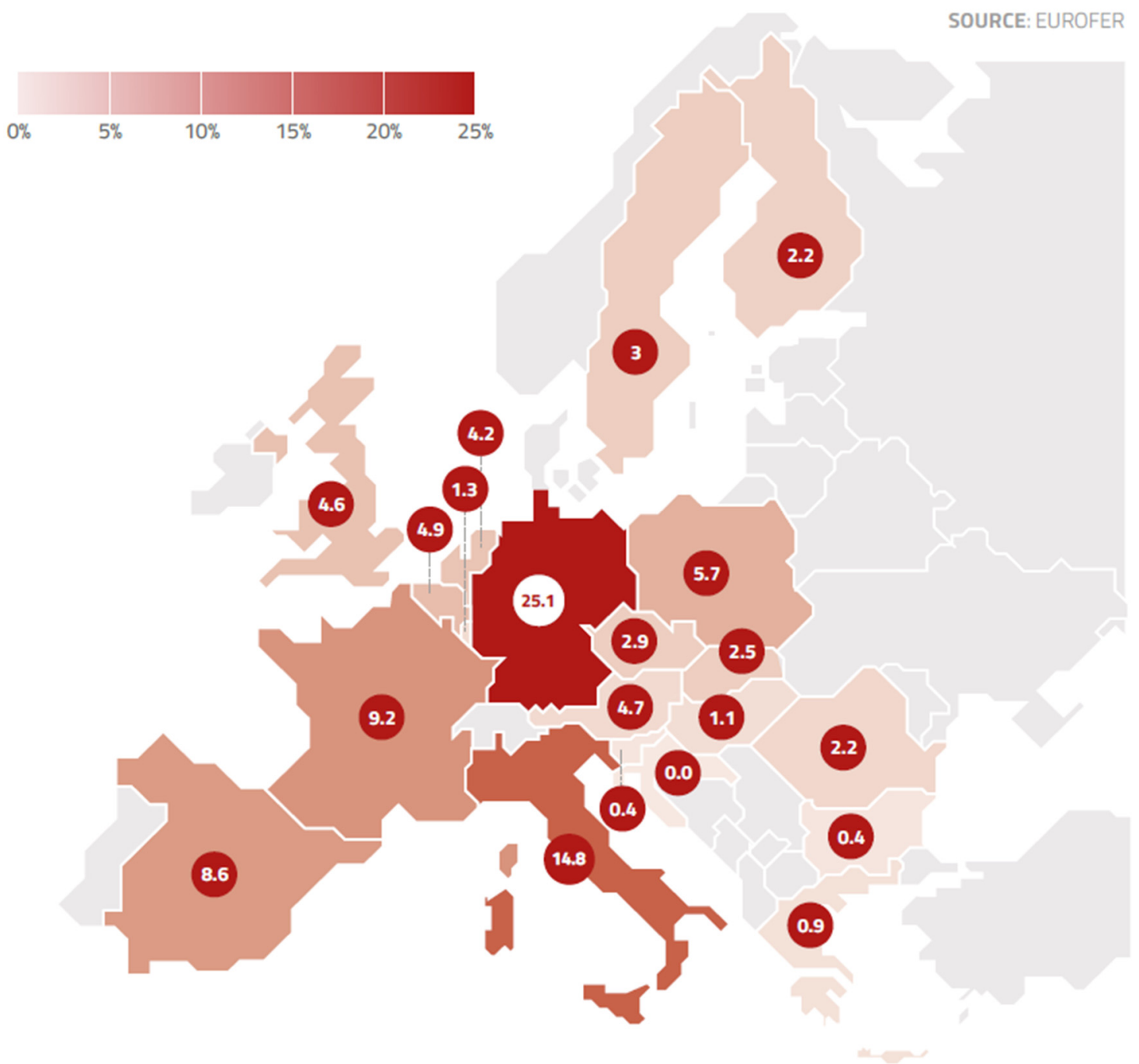

Fig. 1. Relative size of crude steel production in the EU tonnes [3].

using a large percentage of iron units originating from iron ore (e.g. blast furnace route) are capable of producing virtually any type of steel quality whereas the grade of the steel produced via the scrap-EAF route can be limited by the availability of scrap of sufficient quality [4].

In order to reach the climate-neutrality in Europe by 2050 as stated within the Green Deal and keep global warming below $2{ }^{\circ} \mathrm{C}[5]$, the European iron and steel industry is committed to drastically reduce its $\mathrm{CO}_{2}$ emissions, since steel industry accounts for approximately $22 \%$ of Europe's industrial $\mathrm{CO}_{2}$ emissions, according to Roland Berger [6]. Additionally, it is estimated that with the existing production routes, a maximum abatement of $\mathrm{CO}_{2}$ emissions from the European steel sector of $15 \%$ [7] can be achieved by 2050 (with reference to 2010 emissions), even when considering an increased availability and utilization of scrap and a reduction of the $\mathrm{CO}_{2}-$ intensity of the power sector. For this reason, the implementation of so-called "breakthrough technologies" in the steel sector is compulsory in order to reach further $\mathrm{CO}_{2}$ reductions.

\section{Pathways for the decarbonization of the steel industry}

Two main pathways to achieve extensive $\mathrm{CO}_{2}$ reductions in the steel sector can be distinguished, according to EUROFER [8]: Smart Carbon Usage (SCU) and Carbon Direct Avoidance (CDA), as presented in Figure 2. Unlike SCU, which is mainly focused on process-modifications to reduce the carbon usage and the utilization of by-product gases for a further conversion into valuable products; $\mathrm{CDA}$ is centered on fully replacing carbon by renewable electricity or hydrogen. The required hydrogen can be produced for instance by water electrolysis using renewable energy sources. Either the use of hydrogen as an iron ore reducing agent, or the direct utilization of electrical energy for the electrolysis of iron ore, eliminate the formation of $\mathrm{CO}_{2}$, producing instead either water or oxygen. Despite the significant potential of these routes to reduce $\mathrm{CO}_{2}$ emissions, these processes have not yet reached a commercial stage, as they are under different development stages [6]. 


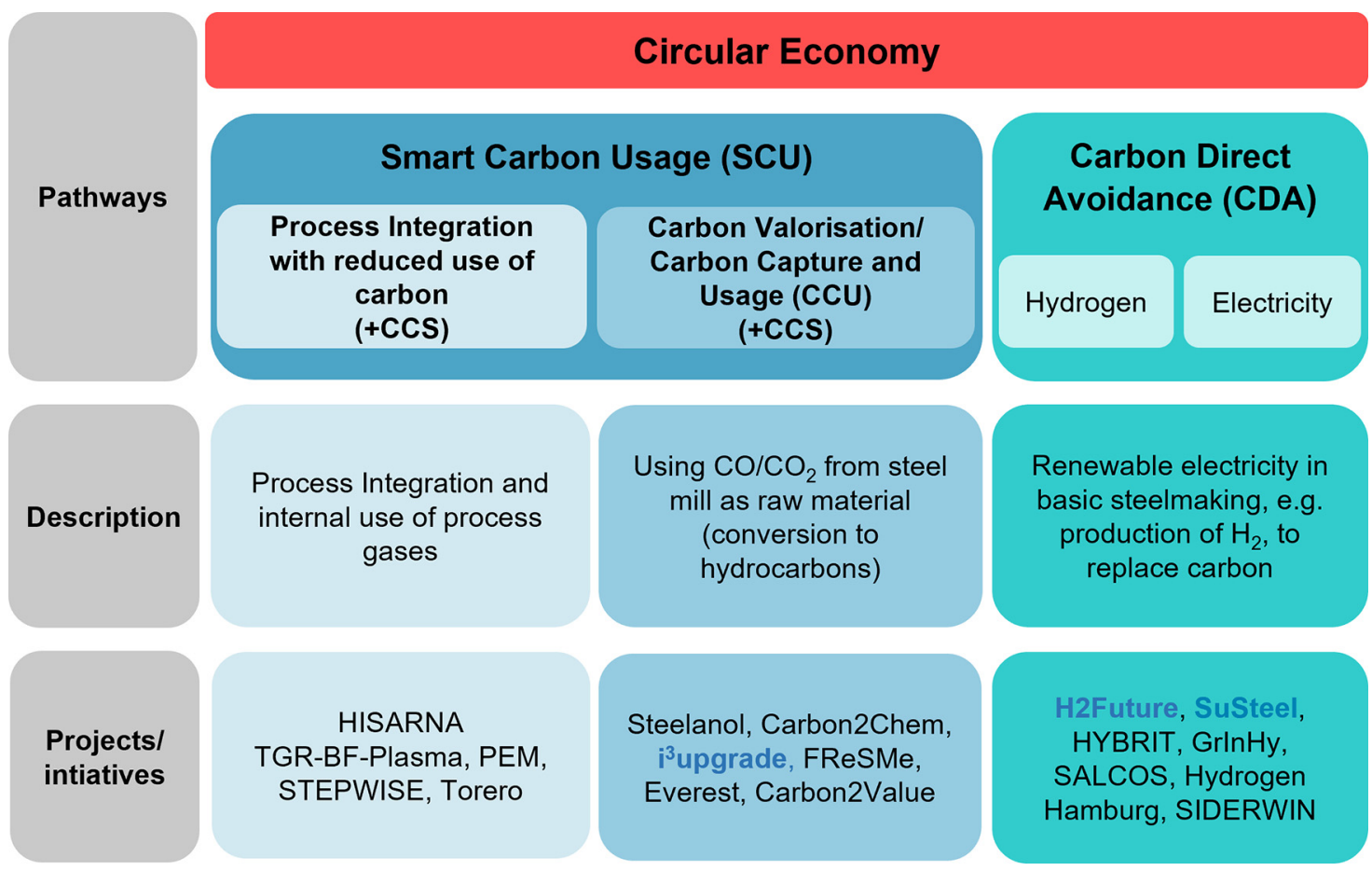

Fig. 2. Technological pathways for the European steel industry [8].

\begin{tabular}{|c|c|c|c|c|c|c|c|c|}
\hline & & $\begin{array}{l}\text { Technology } \\
\text { readiness }\end{array}$ & $\begin{array}{c}\text { Years until } \\
\text { plateau of } \\
\text { productivity }\end{array}$ & $\begin{array}{l}\text { Develop- } \\
\text { ment } \\
\text { costs' }\end{array}$ & $\begin{array}{l}\text { CAPEX } \\
\text { require- } \\
\text { ments }^{2}\end{array}$ & $\begin{array}{l}\text { Operating } \\
\text { costs }^{2}\end{array}$ & $\begin{array}{c}\text { Public } \\
\text { acceptance }\end{array}$ & $\begin{array}{c}\text { Possibility } \\
\text { to transform } \\
\text { brownfield plant }\end{array}$ \\
\hline \multirow{2}{*}{ Ч્త } & $\begin{array}{l}\text { Carbon capture, use and/or } \\
\text { storage }\end{array}$ & & $5-10$ & & & & & \\
\hline & $\begin{array}{l}\text { Carbon capture, use and/or } \\
\text { storage with biomass }\end{array}$ & & $5-10$ & & & & & \\
\hline \multirow{5}{*}{ 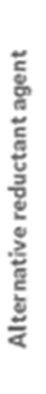 } & $\begin{array}{l}\mathrm{H}_{2} \text {-based direct reduced } \\
\text { iron - Shaft furnace }\end{array}$ & & $0-3$ & & & & & \\
\hline & $\begin{array}{l}\mathrm{H}_{2} \text {-based direct reduced } \\
\text { iron - Fluidized bed }\end{array}$ & & $5-15$ & & & & & \\
\hline & $\begin{array}{l}\text { Suspension ironmaking } \\
\text { technology }\end{array}$ & & $17-22$ & & & & & \\
\hline & $\begin{array}{l}\text { Plasma direct steel } \\
\text { production }\end{array}$ & & $20-25$ & & & & & \\
\hline & $\begin{array}{l}\text { Electrolytic } \\
\text { processes }\end{array}$ & & $20-30$ & & & & & \\
\hline
\end{tabular}

Fig. 3. Comparison $\mathrm{CO}_{2}$ mitigation technologies [6].

Iron ore electrolysis systems such as low temperature iron electrowinning or high-temperature electrolysis belong to those CDA processes, which ought to be powered by renewable energy [9]. Hydrogen plasma smelting reduction or the direct reduction with hydrogen are among the CDA processes where carbonaceous reducing agents are replaced by hydrogen.
The direct reduction with natural gas, has received particular attention as a bridge technology, since it is a process, which can be adapted to the usage of hydrogen as a single reducing agent. Direct reduction with natural gas $\left(\mathrm{DR}\left(\mathrm{CH}_{4}\right)\right)$ is already an established production process, which operates with a mixture of hydrogen and carbon monoxide (produced by the reforming of natural gas) and 


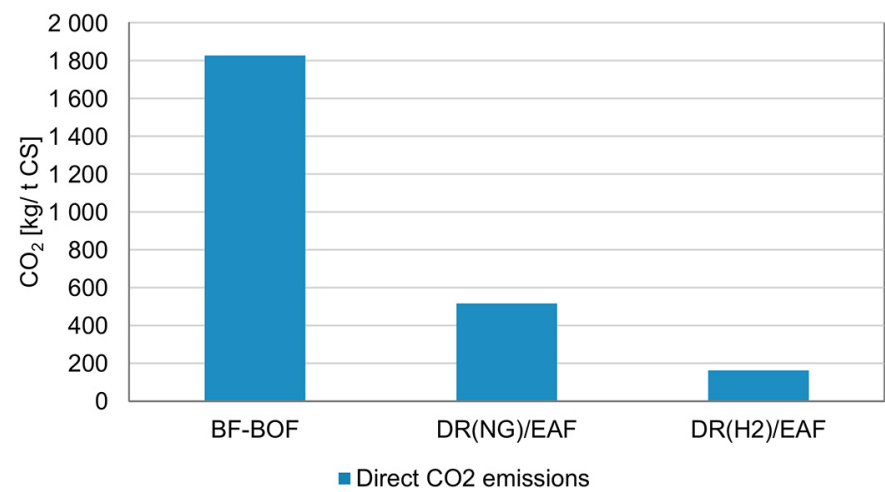

Fig. 4. $\mathrm{CO}_{2}$-emissions from $\mathrm{BF} / \mathrm{BOF}, \mathrm{DR}\left(\mathrm{CH}_{4}\right) / \mathrm{EAF}$ and $\mathrm{DR}$ $\left(\mathrm{H}_{2}\right) / \mathrm{EAF}$.

therefore provides significant $\mathrm{CO}_{2}$ savings compared to the integrated route (BF/BOF). However, the achievable $\mathrm{CO}_{2}$ abatement potential when operating only with natural gas is not sufficient to reach the carbon reduction goals. Nevertheless, since $\mathrm{DR}\left(\mathrm{CH}_{4}\right)$ already operates partly with hydrogen, additional amounts of this gas might be implemented to the system to achieve a further $\mathrm{CO}_{2}$ reduction. For this reason, $\mathrm{DR}\left(\mathrm{CH}_{4}\right) / \mathrm{EAF}$ could act as a bridge technology between the current production process; the blast furnace in combination with the basic oxygen furnace $(\mathrm{BF} / \mathrm{BOF})$; and the direct reduction with hydrogen $\left(\mathrm{DR}\left(\mathrm{H}_{2}\right) / \mathrm{EAF}\right)$. Furthermore, and according to a recent publication [6], $\mathrm{DR}\left(\mathrm{H}_{2}\right)$ possesses one of the highest Technology Readiness Levels (TRLs) and lowest development costs when compared with other $\mathrm{CO}_{2}$ mitigation technologies (see Fig. 3). Thus, its commercial implementation could take place within a relatively short period of time.

\section{Techno-economic assessment}

Three different production routes were studied in this paper as a possible sequence pathway to the decarbonization of the steel industry: (1) BF/BOF, (2) $\mathrm{DR}\left(\mathrm{CH}_{4}\right) / \mathrm{EAF}$ and (3) $\mathrm{DR}\left(\mathrm{H}_{2}\right) / \mathrm{EAF}$, where the direct reduction with natural gas acts as a bridge technology between the current predominant production route $(\mathrm{BF} / \mathrm{BOF})$ and the low carbon steelmaking process $\left(\mathrm{DR}\left(\mathrm{H}_{2}\right) / \mathrm{EAF}\right)$.

The present work is mainly focused on the technoeconomic aspects from the transition of the steel industry towards a low carbon steel production as the $\mathrm{BF} / \mathrm{BOF}$ and $\mathrm{DR}\left(\mathrm{CH}_{4}\right) / \mathrm{EAF}$ are widely known processes, since they are part of the contemporary steel production processes. The feasibility of the production of steel by direct reduction with hydrogen has already been described in numerous research studies [10-13].

In order to complete a techno-economic analysis, the determination of the energy and material requirements, $\mathrm{CO}_{2}$ emissions, etc. from the three above-mentioned processes was first required. Consequently, process simulation models were developed, since up to now no commercial direct reduction process operated with hydrogen is existing and $\mathrm{BF} / \mathrm{BOF}$ and DR/EAF are two different processes with individual operating characteristics.
A comprehensive evaluation of the entire process chain was therefore performed. Simulation models for the abovementioned processes were first developed and validated with literature data. Data inputs for the process and economic evaluation were taken from literature and are often generic in nature. The models were set up in a process simulation platform using the m.SIMTOP ${ }^{\circledR}$ model library for metallurgical processes; developed by Primetals Technologies and voestalpine in recent years.

\section{Results and discussion}

As previously indicated, an extensive reduction of the $\mathrm{CO}_{2}$ emissions from the steel industry is not achievable with current commercial production routes. Nevertheless, the iron and steel industry is committed to reach large $\mathrm{CO}_{2}$ reductions by 2050 . Therefore, the $\mathrm{CO}_{2}$-reduction potentials from the direct reduction hydrogen route in comparison with the current production routes, $\mathrm{DR}\left(\mathrm{CH}_{4}\right) / \mathrm{EAF}$ and $\mathrm{BF} / \mathrm{BOF}$, were analyzed in detail with the help of the simulation models. This analysis was performed prior to the cost evaluation, in order to ascertain whether sufficient $\mathrm{CO}_{2}$ savings could be reached with the hydrogen-based direct reduction route, as only limited information regarding this topic was available $[3,14]$.

To get a complete overview of the direct $\mathrm{CO}_{2}$-emissions coming from the three different production routes, the emissions resulting from the core processes as the blast furnace, basic oxygen furnace, direct reduction shaft and electric arc furnace, together with the sintering and coking plant were included among the direct emissions. Emissions from the coking and sintering plant were integrated in the $\mathrm{BF} / \mathrm{BOF}$ overall $\mathrm{CO}_{2}$-assessment since both processes present relevant $\mathrm{CO}_{2}$ emissions. The power plant $\mathrm{CO}_{2}-$ emmisions; linked with the utilization of by-product gases from the coking, BF- and BOF-process for electricity generation; were also treated as direct emissions.

Figure 4 shows the direct emissions calculated for the 3 studied production routes for every ton of crude steel (CS) produced: (1) $\mathrm{BF} / \mathrm{BOF},(2) \mathrm{DR}\left(\mathrm{CH}_{4}\right) / \mathrm{EAF}$ and (3) $\mathrm{DR}\left(\mathrm{H}_{2}\right) / \mathrm{EAF}$ with $\sim 1,830 \mathrm{~kg} \mathrm{CO}_{2} / \mathrm{t}, \sim 520 \mathrm{~kg} \mathrm{CO}_{2} / \mathrm{t} \mathrm{CS}$ and $160 \mathrm{~kg} \mathrm{CO}_{2} / \mathrm{tCS}$, respectively. This translates into a $\mathrm{CO}_{2}$ reduction potential of about $72 \%$ and $91 \%$ for the DR $\left(\mathrm{CH}_{4}\right) / \mathrm{EAF}$ and the $\mathrm{DR}\left(\mathrm{H}_{2}\right) / \mathrm{EAF}$ respectively, in comparison with the blast furnace route.

For the techno-economic analysis, only direct emissions were considered since the upstream emissions (as for example from the lime and pelletizing plant) represent a minor share of the overall $\mathrm{CO}_{2}$ emissions. Consequently, only the carbon footprint of the core processes was considered.

The source of electricity used to generate hydrogen has a large role on in-direct emissions. In order to avoid indirect emissions, hydrogen should be produced from a renewable source. The overall efficiency and flexibility of hydrogen generation also plays an important role in both technical viability and economics of the $\mathrm{DR}\left(\mathrm{H}_{2}\right) / \mathrm{EAF}$ route.

There are several types of electrolysers differing in electrolyte material, operating temperatures, pressures, degree of maturity and capacity regarding dynamic 
Table 1. Parameters used for the calculations.

\begin{tabular}{|c|c|c|c|c|}
\hline Description & Units & 2020 & 2030 & 2050 \\
\hline$\overline{N G^{1}}$ & $€ / M W h$ & $18.5[21]$ & $21.7[24]$ & $22.5[24]$ \\
\hline $\mathrm{CO}_{2}$ & $€ / \mathrm{tCO}_{2}$ & $24.6[23]$ & $74.5[24]$ & $160.7[24]$ \\
\hline Electricity $^{1}$ & $€ / M W h$ & $54.6[22]$ & $0-100$ & $0-100$ \\
\hline
\end{tabular}

${ }^{1}$ Prices excluding taxes and levies for non-household consumers.

operation. Alkaline electrolysis (AEL), proton exchange membrane electrolysis (PEM) and solid oxide electrolysis (SOEC) are highlighted as the main electrolysis technologies [15]. As a result of its rapid response facing fluctuations in the power supply (due to renewables), PEM technology seems to be a promising option for the production of hydrogen from renewable sources

For this reason, as a part of the H2FUTURE project, a 6-MW polymer electrolyte membrane (PEM) electrolysis system was installed at the voestalpine steelworks in Linz, Austria; to validate the ability of the electrolyser, to use power price opportunities to produce hydrogen [16]. The outcomes from the project were used in the current calculation analysis.

\subsection{Crude steel production cost analysis}

The crude steel production costs under the current technical and economic conditions for the 3 studied cases: (1) $\mathrm{BF} / \mathrm{BOF},(2) \mathrm{DR}\left(\mathrm{CH}_{4}\right) / \mathrm{EAF}$ and (3) $\left.\mathrm{DR}\left(\mathrm{H}_{2}\right) / \mathrm{EAF}\right)$, were studied and are presented in this section.

A cost-calculation tool supported by the simulation results as well as by literature sources [17-27] was developed. For the calculation process, production costs were then divided into "constant costs" as the raw materials-, service-, labor- and capital costs (wear and tear) [25] and "changeable costs". In contrast to the "constant costs" which are independent from any economic or political scenario, the "changeable costs" are strongly influenced by external factors and are therefore subject to sensitivity analysis. The "changeable costs" include the costs of electricity, natural gas, direct $\mathrm{CO}_{2}$ emissions, or the costs of the electrolyser. Only the direct $\mathrm{CO}_{2}$ processemissions were considered here, since the corresponding $\mathrm{CO}_{2}$-costs from the upstream- and indirect (linked to electricity generation) emissions were already taken into account in the prices from these calculations.

All costs and price information were taken from literature sources and should be considered as generic values. Specific and actual costs can vary both regionally and depending upon market conditions. Additionally, as the goal is the comparison of the relevant routes, the $\mathrm{CO}_{2}$ price (see Tab. 1) was applied to all direct $\mathrm{CO}_{2}$ emissions for each case, which does not necessarily reflect the existing allowances available under the EU ETS system.

Figure 5 shows that under the present economic conditions, the calculated production costs for the $\mathrm{BF} /$ $\mathrm{BOF}, \mathrm{DR}\left(\mathrm{CH}_{4}\right) / \mathrm{EAF}$ and $\mathrm{DR}\left(\mathrm{H}_{2}\right) / \mathrm{EAF}$ pathways are: 490,487 and $669 € / \mathrm{t}$ of crude steel respectively, considering the current electricity, natural gas (NG) and $\mathrm{CO}_{2}$ prices presented in Table 1 . Therefore, with the assumptions used

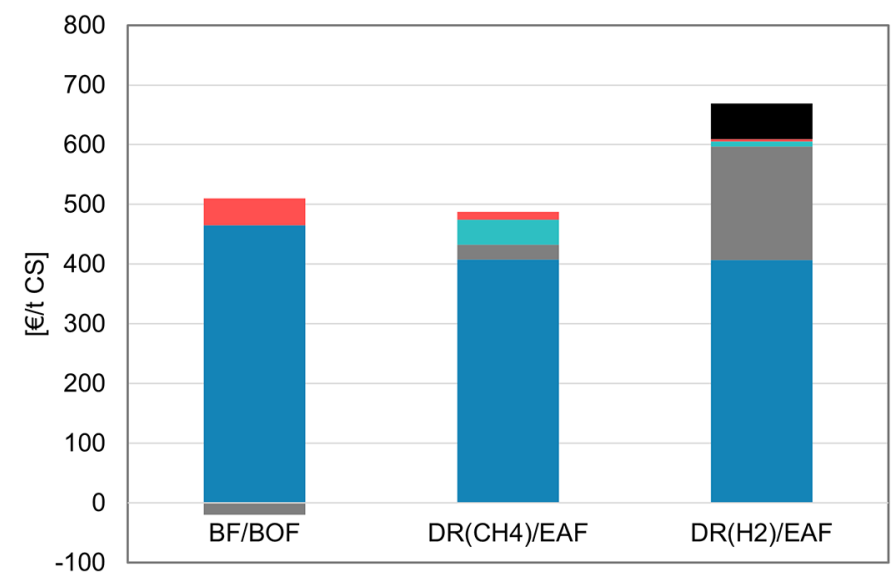

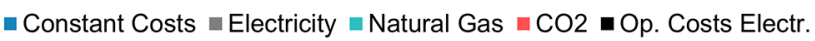

Fig. 5. Crude steel production costs overview.

in this analysis, the production costs of crude steel today through the $\mathrm{BF} / \mathrm{BOF}$ and $\mathrm{DR}\left(\mathrm{CH}_{4}\right)$ route are approximately on the same level. It should be noted that this does not consider the additional capital costs required to transition from an existing brown-field integrated production to a DR/EAF based route. The shift of the production from the BF to the hydrogen route will entail a $36 \%$ increase in the production costs; due mainly to the electricity prices and costs ascribed to the electrolyser.

It must be noted that the figures taken for the calculations regarding the electricity, natural gas, or $\mathrm{CO}_{2}$, are European mean values (Tab. 1). Consequently, the cost-outlook will be different for every European country depending on its own electricity and natural gas prices.

Constant costs present similar values for the three production pathways. Therefore, the changeable costs will be the influencing factor in the overall cost calculation. For the $\mathrm{BF}$ route, the direct $\mathrm{CO}_{2}$ emissions are responsible for $10 \%$ of the total costs whereas a $5 \%$ credit is linked to the revenues obtained from electricity production utilizing the process gases (in the balance limits a further utilization of process gases in the steel mill has not been considered).

The situation results look different for the direct reduction with natural gas and hydrogen. The cost distribution for the direct reduction process with natural gas shows that natural gas, electricity and $\mathrm{CO}_{2}$-emission costs represent $10 \%, 7 \%$ and $3 \%$, of the total costs respectively. However, the costs linked to the electricity consumption for the hydrogen route, are seven times 


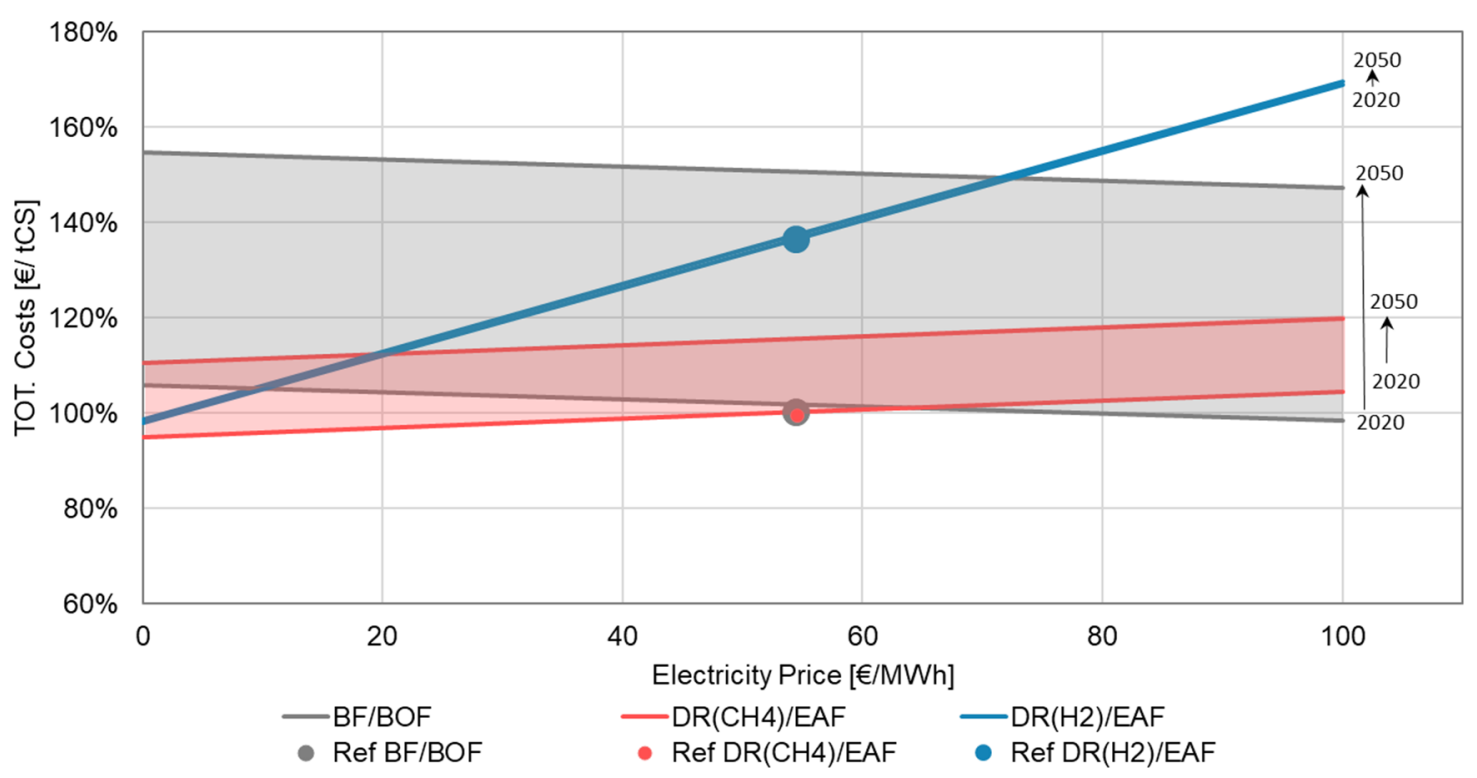

Fig. 6. Break-even ranges.

higher. Additionally, the costs corresponding to the electrolyser, which entail approximately $9 \%$ of the total costs, should be added to it.

\subsection{Break even ranges}

The goal of this techno-economic study is to find out in which point of time and under which technical and economic conditions the production of steel via the direct reduction route with hydrogen becomes an economically realistic solution for the European steel industry. For this reason, after determining the crude steel costs under the current technical and economic conditions, estimated production costs for different scenarios were calculated.

As presented in Figure 5, variables such as electricity-, $\mathrm{CO}_{2^{-}}$, NG-price, the investment costs of the electrolyser, etc. play a significant role in the production cost of crude steel, since those parameters represent a relevant share of the production costs and they may suffer noticeable deviations from its current values over time (Tab. 1). NG and $\mathrm{CO}_{2}$ prices were assumed to vary according to the "sustainable scenario" defined by the International Energy Agency, and the costs coupled to the electrolyser such as the capital and operational costs were obtained from the H2FUTURE project results. Regarding the electrical energy prices, those were limited to a range between 0 and $100 € /$ MWh. On the other hand, the "constant costs" for the three routes remain unchanged over time. Table 1 encompasses the assessments gathered for this work for 2020, 2030 and 2050.

Based on these assumptions and taking the $\mathrm{BF} / \mathrm{BOF}$ route as the reference process, the overall production costs for 2030 and 2050 were calculated
Once the current and potential cost of the three production routes were determined, it was possible to define the allowable costs of electricity for an economically viable hydrogen-based steel production. The break-even ranges for the costs of the three steel production routes were analysed, as a function of the electricity costs over time. Figure 6 shows the break-even ranges for the $\mathrm{BF} /$ $\mathrm{BOF}, \mathrm{DR}\left(\mathrm{CH}_{4}\right) / \mathrm{EAF}$ and $\mathrm{DR}\left(\mathrm{H}_{2}\right) / \mathrm{EAF}$ routes for 2020 and 2050.

The three dots shown in Figure 6 display the current production costs for the three studied routes as presented in Figure 5. Although electricity price has an impact on the production cost of both process routes $\mathrm{BF} / \mathrm{BOF}$ and $\mathrm{DR}\left(\mathrm{CH}_{4}\right) / \mathrm{EAF}$, it is not as dramatic as the impact electricity has on the $\mathrm{DR}\left(\mathrm{H}_{2}\right) / \mathrm{EAF}$ route. The production costs of both processes will remain roughly uniform over the electricity price range from $0-100 € / \mathrm{MWh}$. Nevertheless, since the price for the $\mathrm{CO}_{2}$ emissions may increase significantly for 2050, the production costs of crude steel through the $\mathrm{BF} / \mathrm{BOF}$ route compared to the $\mathrm{DR}\left(\mathrm{CH}_{4}\right) / \mathrm{EAF}$ will be visibly higher (due to the strong influence of the $\mathrm{CO}_{2}$-costs on the production costs of the $\mathrm{BF} / \mathrm{BOF}$ route). An increase of up to $50 \%$ on the crude steel produced via the $\mathrm{BF} / \mathrm{BOF}$ route may be expected based on the forecast $\mathrm{CO}_{2}$ price scenario outlined by the IEA.

It can also be noticed that with the current prices for the $\mathrm{NG}, \mathrm{CO}_{2}$ and electrolyser, the hydrogen route will be less profitable than the natural gas-based route. The production costs evolve nevertheless differently by 2050 , and it can be seen in the figure below that an electricity price of around $20 € / \mathrm{MWh}$ is required in order to have similar production costs as the natural gas based DRI route. 


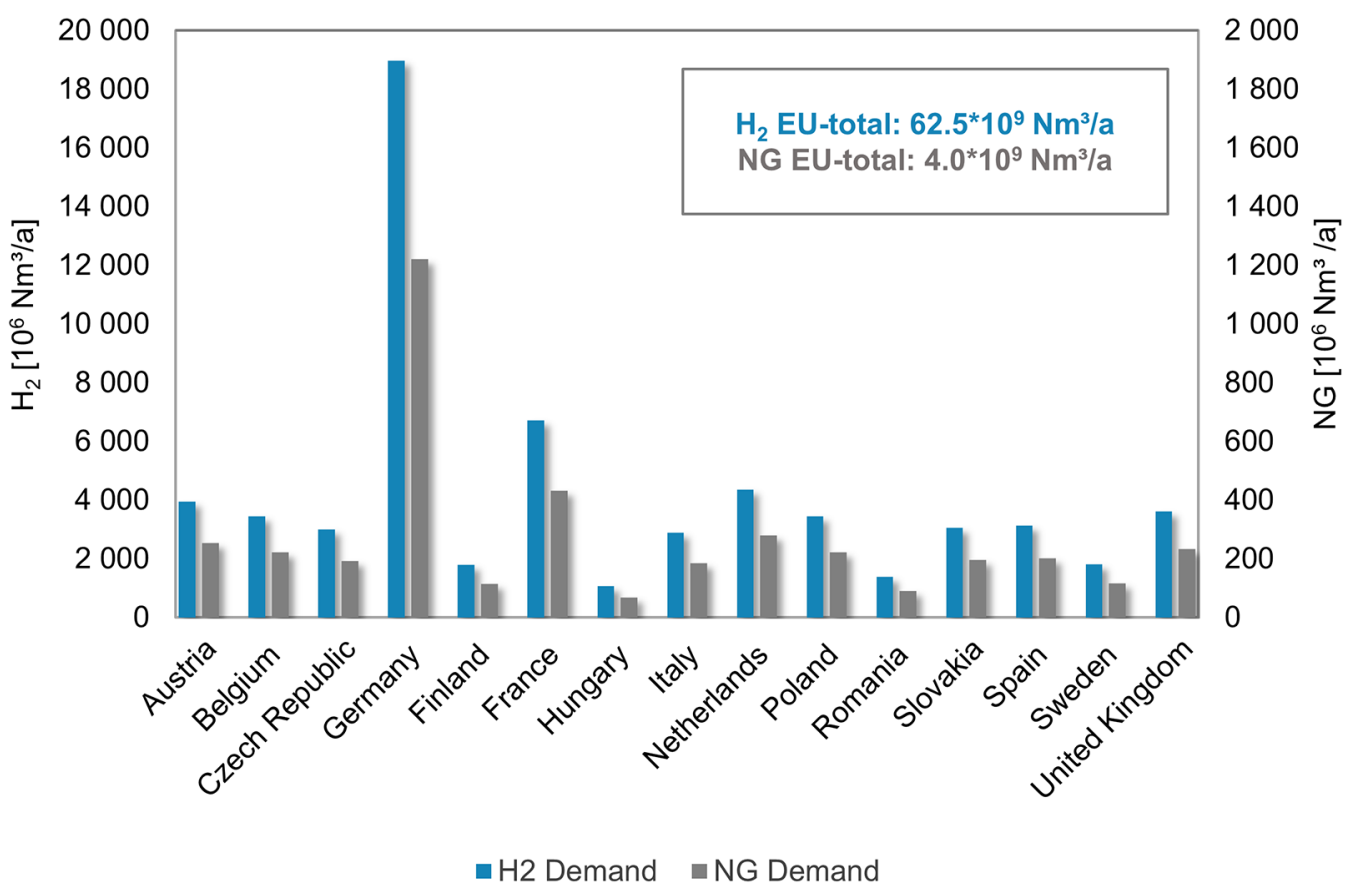

Fig. 7. Hydrogen and natural gas demand for Europe steel production.

When comparing the production costs, only between the BF- or the $\mathrm{H}_{2}$ route, and assuming the cost situation of 2050 (see Tab. 1), the hydrogen route becomes economically interesting below an electricity price of around $74 € /$ MWh. On the other hand, at the current situation, the electricity price would have to fall below $10 € / \mathrm{MWh}$. It is once again important to note that this break-even cost does not include the capital investment required to switch from an existing $\mathrm{BF}$ route to a DR based route.

However, a further decrease in the investment, operation and maintenance costs of electrolysers could change the situation favouring $\mathrm{H}_{2}$ instead of NG.

\subsection{Energy and hydrogen demand}

The hydrogen demand and subsequent electricity requirements for the complete shift of the European steel industry towards a carbon lean production is analyzed in this section.

For the calculations, it was assumed to shift from the entire crude steel production from $\mathrm{BF} / \mathrm{BOF}$ route to the $\mathrm{DR}\left(\mathrm{H}_{2}\right) / \mathrm{EAF}$ pathway. This could lead to an overall hydrogen demand for Europe of 62.5 billion $\mathrm{Nm}^{3} / \mathrm{a}$ and an additional amount of 4 billion $\mathrm{Nm}^{3}$ of $\mathrm{NG}$ (to maintain the carbon content in the DRI produced). The current amount of crude steel manufactured through the scrap/EAF route was not considered for the calculations, since this steel is not produced from virgin iron ores. Scrap will continue to be generated, since the steel produced via the DR/EAF will be recycled at the end of its life.

The $\mathrm{H}_{2}$ and NG- demand for the different countries in Europe is shown in Figure 7. Those figures were based on the reducing gas-requirements obtained from the simulations: $638 \mathrm{Nm}^{3} \mathrm{H}_{2} / \mathrm{t} \mathrm{CS}$ (crude steel), $41 \mathrm{Nm}^{3} \mathrm{CH}_{4} / \mathrm{t} \mathrm{CS}$.
Germany, France, Netherlands and Austria (with 19 billion $\mathrm{Nm}^{3} / \mathrm{a}, 6.7 \mathrm{bn} \mathrm{Nm}^{3} / \mathrm{a}, \quad 4.3 \mathrm{bn} \mathrm{Nm}^{3} / \mathrm{a}$ and $3.9 \mathrm{bn} \mathrm{Nm}^{3} / \mathrm{a}$ respectively) encompass the countries with the larger hydrogen requirements among de EU zone since those countries are the largest steel producers via the $\mathrm{BF} / \mathrm{BOF}$ route.

The use of alternative energy sources for hydrogen preheating in the direct reduction process (instead of hydrogen itself), together with an increased use of the scrap in the EAF, could minimize the hydrogen requirements of the production process.

The shift from carbonaceous reducing agents to hydrogen will lead to a significant increase of the electricity demand. Therefore, the electrical requirements from the single European countries were analyzed. With $103 \mathrm{TWh} / \mathrm{a}$, Germany becomes the country with the largest electricity demand (Fig. 8); accounting approximately with one third of the European energy demand for the shift, since additional $340 \mathrm{TWh}$ will be required for Europe annually. About $300 \mathrm{TWh} / \mathrm{a}$ from this $340 \mathrm{TWh} / \mathrm{a}$ are intended to cover the electrical necessities for the production of $\mathrm{H}_{2}$ and the remaining $40 \mathrm{TWh} / \mathrm{a}$, correspond to the electricity needs for the EAF- and the DR-process itself. In many integrated works, the electricity for the downstream operations is supplied by power plants on the facility, which are powered by the various off gases from steel production. However, when turning into a low carbon steel industry, other steel production processes will be used, and those gases will therefore no longer be available. Thus, the corresponding energy demand will have to be covered by renewables. The calculation of the green energy requirements for the downstream processes is out of scope of this study, as the balance borders of this analysis conclude with the production of crude steel. 


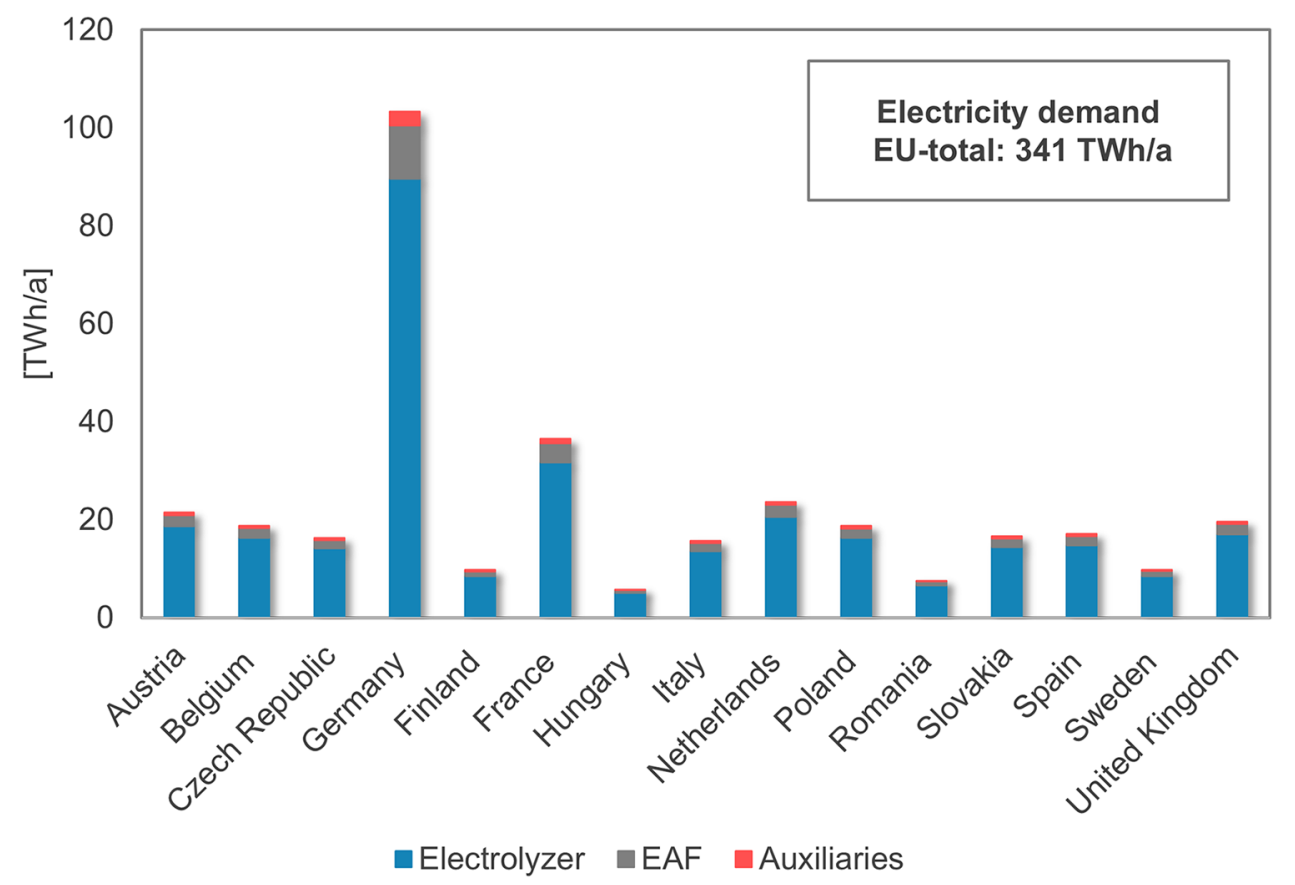

Fig. 8. Additional electricity demand for European steel production.

Therefore, no secondary metallurgical processes are considered here, to facilitate the calculations due to the large product portfolio of finished products.

Even if the additional energy demand would be lower due to the application of other low-carbon or scrap-based steelmaking routes, the development of suitable electrolysers as well as the supply of sufficient amounts of renewable energy will be a huge challenge for all involved stakeholders, which must be tackled in future.

\section{Conclusion}

To accomplish the objectives for 2050, a shift towards a lean carbon steel production is mandatory and therefore the implementation of the so-called breakthrough-technologies. Since nowadays the direct reduction with hydrogen seems to be one of the most promising processes to achieve such $\mathrm{CO}_{2}$ reductions in a short period of time, as seen in Figure 3, a detailed evaluation and comparison with the existing steelmaking technologies was conducted within this work.

However, the availability of large amounts of green hydrogen is one of the prerequisites to achieve the abovementioned goal, since the overall $\mathrm{CO}_{2}$-footprint of the direct reduction with hydrogen significantly depends on the $\mathrm{CO}_{2}$-intensity of the electricity used for the hydrogen production. This implies a deep decarbonization of the electricity sector as one of the prerequisites for green steelmaking and the technological development and upscale of electrolysers. Another key aspect is the large increase of the electricity demand, which has to be covered by renewable energy challenging all involved stakeholders.

One of the main influencing factors on the hydrogenbased process are the electricity prices. Therefore, for the economic viability of the hydrogen-based steelmaking low and stable electricity prices are required.
To summarize, the direct reduction with hydrogen is a promising process for the decarbonization of the steel industry. Nevertheless, important requirements as the up-scale of the electrolyser technology, low electricity prices as well as the supply of sufficient amounts of renewable electricity must be available to allow such a transition.

Conflicts of interest. The authors declare that they have no conflicts of interest in relation to this article.

Acknowledgements. This study was carried out during the H2FUTURE project, which received funding from the Fuel Cells and Hydrogen 2 Joint Undertaking under the grant agreement No.735503. This Joint Undertaking receives support from the European Union's Horizon2020 research and innovation programme and Hydrogen Europe and N.ERGHY.

\section{References}

1. World Steel Association, Steel Statistical Yearbook 2019, World Steel Association, 2019

2. P. Dahlmann, H.B. Lüngen, M. Sprecher, Steel roadmap for low carbon Europe 2050, in: Technical results, in European steel technology and application days, Düsseldorf, 2019

3. EUROFER, European steel in figures 2020, EUROFER, 2020

4. M. Wörtler, F. Schuler, N. Voigt, et al., Steel's contribution to a low-carbon Europe 2050, The Boston Consulting Group, Steel Instiute VDEh, 2013

5. European Commission, The European Green Deal, European Commission, Brussels, 2019

6. A. Ito, A. Lecat, The future of steelmaking - How the European steel industry can achieve carbon neutrality, Roland Berger, 2020

7. EUROFER, A steel roadmap for a low carbon Europe 2050, EUROFER, 2013 
8. EUROFER, Low carbon roadmap. Pathways to a $\mathrm{CO}_{2}$ neutral European steel industry, EUROFER, Brussels, 2019

9. M. Draxler, Carbon direct avoidance, in: LowCarbonFuture Final Webinar, 2020

10. K. Rechberger, A. Spanlang, A. Sasiain Conde, H. Wolfmeir, C. Harris, Green hydrogen-based direct reduction for low carbon steelmaking, Steel Res. Int. 91(11) (2020)

11. V. Vogl, M. Åhman, Assessment of hydrogen direct reduction for fossil-free steelmaking, J. Clean. Prod. 203, 736-745 (2018)

12. M. Hölling, M. Weng, S. Gellert, Bewertung der Herstellung von Eisenschwamm unter Verwendung von Wasserstoff, Stahl und Eisen, 137, 47-53 (2017)

13. J. Ripke, J. Kopfle, MIDREX $\mathrm{H}_{2}$ : ultimatelow $\mathrm{CO}_{2}$ ironmaking and its place in the new hydrogen economy, in: Direct from Midrex, 3rd Quarter 2017, Midrex, 2017, pp. 7-12

14. N. Müller, G. Herz, A. Redenius, V. Hille, E. Reichelt, M. Jahn, Assessment of the transition from coal-based steelmaking to hydrogen-based steelmaking, METEC \& 4th ESTAD, Düsseldorf, 2019

15. A. Zaccara, A. Petrucciani, I. Matino, et al., Renewable hydrogen production processes for the off-gas valorization in integrated steelworks through hydrogen intensified methane and methanol syntheses, Metals 10(11), 1-24 (2020)

16. H2FUTURE Project, https://www.h2future-project.eu/ [Online]
17. M. Weigel, Ganzheitliche Bewertung zukünftig verfügbarer primärer Stahlherstellungsverfahren. Einschätzung der möglichen Rolle von Wasserstoff als Reduktionsmittel, Wuppertal, 2014

18. N. Pardo, J. Moya, K. Vatopoulos, Prospective scenarios on energy efficiency and $\mathrm{CO}_{2}$ emissions in the EU Iron \& Steel Industry, European Commission, 2012

19. V. Chevrier, Slow road to recovery for DR-grade pellets, in: Direct from Midrex. 4th quarter2019, Midrex, 2019

20. IEAGHG, Iron and steel CCS study (techno-economics integrated steel mill), IEAGHG, 2013

21. EUROSTAT, https://appsso.eurostat.ec.europa.eu/nui/ show.do?dataset $=$ nrg_pc_205\&lang $=$ en [Online]

22. EUROSTAT, https://ec.europa.eu/eurostat/databrowser/ bookmark/bed343e6-baa2-4ce6-b2a8-fd3d865715be?lang=en [Online]

23. EEX, https://www.eex.com/en/markets/environmentalmarkets/emissions-auctions [Online]

24. International Energy Agency, World Energy Outlook 2018, International Energy Agency, 2018

25. J. Mayer, G. Bachner, K.W. Steininger, Macroeconomic implications of switching to process-emission-free iron and steel production in Europe, J. Clean. Prod. 1517-1533 (2019)

26. J. Janssen, Hydrogen cost analysis, H2FUTURE, 2019

27. M. Weeda, WP9 impact \& exploitation, in: 7th Steering Committee H2FUTURE, Linz, 2018

Cite this article as: Amaia Sasiain Conde, Katharina Rechberger, Andreas Spanlang, Hermann Wolfmeir, Christopher Harris, Decarbonization of the steel industry. A techno-economic analysis, Matériaux \& Techniques 109, 305 (2021) 